\title{
A Relational Indicatorset Model for urban land-use planning and management: Methodological approach and application in two case studies
}

\author{
Alexandre Repetti ${ }^{a}$, Gilles Desthieux ${ }^{b, *}$ \\ ${ }^{a}$ Ecole Polytechnique Fédérale de Lausanne (EPFL), Hydrology and Land Improvement Laboratory, CH-1015 Lausanne, Switzerland \\ ${ }^{\mathrm{b}}$ Ecole Polytechnique Fédérale de Lausanne (EPFL), Geographic Information Systems Laboratory, CH-1015 Lausanne, Switzerland
}

Received 15 October 2003; received in revised form 12 February 2005; accepted 12 February 2005

\begin{abstract}
Urban land-use planning and management are in constant mutation throughout the world. With sustainability as the goal, the use of indicators for land auditing and monitoring is becoming more and more in demand.

Classical approaches elaborate core sets of indicators by picking the most relevant elements in exhaustive lists. More recently, a few structured research approaches consider the set of indicators as a whole, following the concepts of systemics, and so highlighting the strengths and weaknesses of the sets.

Starting from the principle that the relevance of an indicator is due not only to its intrinsic qualities, but also to its placement and relationships with the other indicators in the collection, this paper proposes a systemic method, named Relational Indicatorset Model (RIM), for the elaboration of a set of indicators for management support.

The RIM method starts with the a priori definitions of the goals and users' purpose (RIM-objectives), and then chooses indicators to reflect the objectives on representing the distribution of indicators in a relational graph (RIM graph). The graph modeling allows analyzing the match between the indicatorset and the defined objectives, as well as the interrelationships between the indicators. The analysis is made easier by breaking down the RIM graph following two projections: the first one (RIM-4D) highlights the distribution of the indicators in a multidimensional graph with respect to the objectives; the second one (RIM-IR) focuses on the interrelationships and offers the possibility of formalizing the causal interactions and the aggregational relationships between the indicators, following a qualitative approach.

The RIM is applied to the design of sets of spatial and non-spatial indicators for the cities of Thies (Senegal) and of Geneva (Switzerland) to emphasize the potential of the method. It opens up interesting possibilities for application to all sets of indicators for sustainable land-use development. It also contributes to the creation of observatories for city management, instruments used to monitor and control the urban sustainable development.
\end{abstract}

(c) 2005 Elsevier B.V. All rights reserved.

Keywords: Urban management; Indicators; Monitoring; GIS; Systemic approach

\footnotetext{
* Corresponding author. Present address: LASIG-EPFL, Station 2, CH-1015 Lausanne, Switzerland. Tel.: +41 21693 5784; fax: +41216935790.

E-mail address: gilles.desthieux@epfl.ch (G. Desthieux).
} 


\section{Introduction}

Indicators are being used more and more frequently in the management of cities, land use, and the environment. But their implementation within institutions remains difficult and a large number of challenges exist in creating a model of urban complexity that is relevant to the needs of its users (OECD, 1997a; Rechatin et al., 1997; Naveh, 2001).

While numerous approaches favor the use of indicators, relevant methodologies are missing to elaborate a set of indicators designed to meet the specific needs of particular situations. The operational and practical aspects, such as the availability and updating of data, are often neglected. Indicators are often represented by indirect evaluations that are barely relevant to the evaluation objectives. They also ignore what is not measurable or quantifiable, such as subjective information related to urban management.

Following two field experiences in designing sets of indicators for urban monitoring, a methodological approach was developed by referring to former methods and to a cross-analysis of the two field experiences. Our Relational Indicatorset Model (RIM) creates a graphical relational system for structuring a set of indicators. This paper presents the methodology and its implementation in the two field experiences, to highlight how it enables structuring sets of indicators for urban land-use management.

The paper first analyses the new challenges in urban development, as well as the main approaches to the elaboration of sets of urban indicators. The RIM method for the design of sets of indicators, based on the RIM graph is then developed and applied to two case studies of urban land-use planning and management in Thies, Senegal, and in Geneva, Switzerland.

\section{The development of indicator-based instruments to meet new challenges in urban management}

\subsection{Urban management}

The traditional idea of urban management consists of the good management and planning of a city, entrusted to the institutional actors (UNDP, 1997). If they are elected representatives of a decentralized govern- ment, the term "local urban management" is preferred (Srinivas, 1999; GHK Group, 2000). The concept of urban management is extensive. Following Borja and Castells (1997), there are five main challenges to managing an urban community: (i) to provide an economic base, (ii) to build urban infrastructure, (iii) to improve the quality of life, (iv) to ensure social integration, and (v) to guarantee governance. The quality of the management depends not only on how well each of these challenges is met, but also on their integration to create coherence in urban development.

Since the 1980s, local management systems have undergone considerable modifications in Europe and more recently in developing countries, driven by the following dynamics:

- A changing relationship between the state and the local communities; especially decentralization and modification of decision processes and financial relationships (le Galès, 1998).

- The emergence of new forms of local governance and new forms of partnerships for management, leading to a redefinition of the frontier between the population, the public sector, and the private sector (le Galès, 1998).

- Following the Rio Summit, ${ }^{1}$ the commitment to sustainable development as a holistic and transsector vision of development that requires integrating management activities and expanding diagnosis and forecasting (Borja and Castells, 1997; Palang et al., 2000; Naveh, 2000; Geertman and Stillwell, 2003a).

- An increase in opposition to projects that negatively affect the environment, for political and economical reasons, but also due to the liberalization and diversification of the media (Luz, 2000; Joerin et al., 2001).

One consequence of these changes is more complex management and broader communication, which make decisions more difficult and increases conflicts. This urban complexity has been debated for decades in developing countries, and today presents an urgent challenge. A slum in Delhi, a "banlieue" in Marseille, or an inner city in Chicago may manifest the same problems, because all cities, in spite of their cultural, historical, and geographic differences, are managed by similar

\footnotetext{
${ }^{1}$ United Nations Conference on the Environment and Development, June 3-14, 1992, Rio de Janeiro.
} 
socioeconomic, political, and urban logic (Bolay et al., 2000).

In order to analyze and control the complexity, cities are often conceived as a dynamic and complex systems, ecosystems (Tjallingii, 1993; Newman, 1999; Naveh 2000; van Kamp et al., 2003) or auto-organizing systems (Repetti and Prélaz-Droux, 2003), made of inputs from its environment, of metabolic interaction betweens its subsystems, and of outputs to the environment.

\subsection{The new challenges of urban management}

In response to the evolution of the urban context, the past several years have seen modifications in management and communication (Geertman and Stillwell, 2003a). The new techniques are more dynamic, derived from economic management principles and information technologies.

First, urban management is becoming more flexible, based on the integration of a strategic global scheme and local management dynamics (Carmona and Burgess, 2001; Ingallina, 2001). It addresses urban project (Borja and Castells, 1997) or spatial or territorial planning (von Stokar et al., 2001), which are flexible tools for management and communication established at the conurbation level. It also includes sustainability concerns and more and more public participation (Borja and Castells, 1997; le Galès, 1998; Shafer et al., 2000). The strategic project is complemented by territorial management, a dynamic tool for analysis and negotiation centered on a continuous audit of the strategic plan (Srinivas, 1999).

Second, urban management deals more with powerful databases and information systems. To face the considerable volume of data, tools are needed to establish overviews of the goals and provide an appropriate level of synthesis. Actors must be able to access all the relevant data without getting lost in the details, nor swamped with information that does not provide a clear picture and is not directly useful for decision making (Allen, 2001; Joerin et al., 2001).

This evolution of management approaches requires new instruments and tools for strategic development, for information update and transmission, and for monitoring the development. There is thus a particular need for indicators, especially spatial indicators, to continuously monitor urban development, control the execu- tion of strategic plans, and compare best practices of management.

\subsection{Indicators for urban management}

An indicator is an empirical and indirect interpretation of reality, but not the reality itself (OECD, 1997a; Merkle and Kaupenjohann, 2000). It is the result of a selection of data (for instance, the follow up of the population as a demographic indicator) or of an aggregation of data that reduces the information (for instance, human development index as an aggregated development indicator). Thus, it promotes a better understanding of complex phenomena and provides a common reference to different stakeholders with various preoccupations.

A set of indicators for urban management constitutes an instrument for observation and for decision (Joerin et al., 2001). It gives to the urban stakeholders a model of city development at a given time and for a definite territorial space (Allen, 2001). A set of indicators has three strategic purposes in urban management (von Stokar et al., 2001):

- Monitoring: a continuous audit of the land in time, comparing its condition at various moments. The indicators give a series of updated images of reality.

- Controlling: an evaluation of the distance that separates the condition at a defined moment from defined objectives or target values. The indicators measure the distance to the defined objectives (Spangenberg et al. 2002).

- Benchmarking: a comparison between territorial entities to find the best practices. The indicators are used as a common base of comparison between the territorial entities (Newman, 1999).

In each one of these types of comparison, the use of indicators is central. In practice, we observe that these roles remain limited, indicators being mainly used as quantitative and static views of a given reality.

\subsection{Designing a set of indicators}

City management is an open and dynamic process, influenced by many outside constraints, related to different themes and multiple management levels. This causes its evolution to be unpredictable. Authors generally agree that there is no generally accepted concepts definition and conceptual framework to measure 
urban quality as the frameworks relates to local policies (Allen, 2001; Harts et al., 2003; van Kamp et al., 2003). Further, urban planning and management is an open or unstructured problem, where the goals and values are not clearly formalized and do evolve (Geertman and Stillwell, 2003b). Thus, it is impossible to establish a fixed collection of information for all purposes of decision-making. Thus, the solution is to display a coherent image of urban development through a sound understanding of the whole urban system. Designing a relevant set of indicators requires then appropriate methods and must avoid several methodological traps.

First, numerous approaches propose simple collections of indicators, as many as one hundred (United Nations, 1996). However, excessive information collection does not provide a clear interpretation of a given situation: it goes against the objective of simplification. On the other hand, an overaggregated indicator does not adequately represent urban complexity, especially when it results from aggregating opposite trends or antinomies (Bell and Morse, 2000). Finally, a set of indicators should be flexible enough to respond to the different needs of urban management at the different levels and scales of the urban system.

Second, indicators are used to evaluate the performance of the system. Thus, standards or target values are required to define the objectives and evaluate the strategies. However, the establishment of these standards is not based on "facts", but is often based on expert assumptions and negotiations of interests. Instruments have therefore been developed to define standards from trend analyses (OECD, 1988; von Stokar et al., 2001; UN-Habitat, 2002; World Bank, 2002). Such approaches aim at determining the desired progress of an indicator in regard to an objective.

Third, in order to follow up on and audit political actions in the course of time, indicators should not only describe a present condition, but also integrate the dynamics of the system (Allen, 2001; Harris and Batty, 2001). The question is then to know in which direction the system evolves: is it going toward or away from the desired progress?

Finally, the objective of good communication is not always in harmony with representing statistical indicators in tables. Graphically representing the spatial heterogeneity and variability of territorial phenomena can enhance this type of information. Thanks to Geographic Information Systems (GIS), which stores basic data and performs spatial analysis, it is possible to construct spatial indicators that are more comprehensible to a large audience (Allen, 2001; Harts et al., 2003; Lautso, 2003). Maps are often more accessible than tables of data.

To gain a sound understanding of the whole urban system, the relational linking of indicators goes further than a collection of static pictures of reality. Linking enables understanding the functioning of the system by emphasizing effects and causal chains. This could be illustrated through an "urban quality" diagnosis that would aim, like in medicine, at seeking welfare by analyzing, sorting and coupling symptoms, like urban sprawl, traffic jam, unemployment, etc.

\subsection{Designing sets of indicators: toward a systemic structure}

In the beginning of the 1990s, following the emergence of the concept of sustainable development, several collections of indicators were designed for gauging the efficiency of projects according to their influence on the environment, society, economy, and future generations. Three main methods have been proposed to structure these large collections:

- The sector-based approach starts from a systematic classification of the indicators in a framework of "Pressure-State-Response" (PSR) (OECD, 1993). It is based on a parallel description of environmental, economic, social, and institutional or political concerns (United Nations, 1996; OECD, 1997b, 2001).

- The intersector approach focuses on the relationships between the sectors (e. g. social distribution of income). It is used in applications like the Hammond et al. (1995) approach and the Wuppertal approach (Spangenberg et al., 2002).

- The indirect approach, such as the phenomenological methods (Prescott-Allen, 1995) associate sustainable development with a small number of phenomena.

These three methods generally aim at designing exhaustive collections of indicators with a strong statistical connotation. The relevance of each indicator is considered with regard to the application context (IFEN, 1998; de Montmollin and Altwegg, 2000) and the indicators are put together in the form of collections, but are not presented in the form of systems. In the PSR 
model, we observe that some indicators show correlations links between different sectors. However, these relationships are not highlighted or used as a structuring base, expressing the interdependence between phenomena or enabling understanding the dynamics of the processes. These approaches are well adapted for the comparison of world regions, but their use in local management remains limited.

Rechatin et al. (1997) have proposed a more innovative structuring method, defining the conditions necessary for the elaboration of a coherent set of indicators. The originality of their approach lies mainly in focusing on the properties of the set as a whole and not of the indicators individually. They address, among other things, the suitability of the objectives, the multidimensionality, the diversity of the geographic scales, and the number of indicators. Their method is based on an analysis of the strengths and weaknesses of several approaches. It leads the way toward a definite structuring method for a set of indicators, according to the a priori defined goals of the evaluation. It is no longer a matter of selecting relevant indicators from an exhaustive list, but of assessing if the set is relevant as a whole.

The use of a set of indicators would be easier if all the indicators were independent. Indeed, a manager could plan actions in order to improve an arena in which the indicators are unsatisfactory without fear that these actions might weaken other arenas. Yet this model is incompatible with the reality of a city that can be analyzed as a complex and dynamic ecosystem made of entities and fluxes (Huang et al., 1998; Newman, 1999). Consequently, the alternative is to make explicit the interrelationships between indicators, in order to understand real dynamic processes and to propose locally relevant and effective sets of indicators (Malkina-Pykh, 2002; Gallopin, 1997; van Kamp et al., 2003).

The concept of interrelationships between indicators is more and more used in the design of urban indicators. For example, the Sustainable Seattle initiative ${ }^{2}$ explicitly proposes the concept of complementary indicators; thus, the linkage of each indicator with others is clearly highlighted (Sustainable Seattle, 1998). Another example is the Global Urban Observatory initiative $^{3}$ from UN-Habitat; it proposes six transversal indexes that link the indicators and themes with

\footnotetext{
2 http://www.sustainableseattle.org/.

3 http://www.unchs.org/programmes/guo/.
}

others (UN-Habitat, 2001, 2002). Finally, the Sustainable Cities ${ }^{4}$ initiative from the European Commission proposes a structured with six main transversal concerns, each indicator relating to one or several concerns (Ambiante Italia, 2003). These three examples all propose different ways for expressing qualitative interrelationships. Now, they do not formalize their methodology and do not propose a clear method for identifying interrelationships nor analyze the resulting model.

We assume that interrelationships between indicators are causal or aggregative ${ }^{5}$ and can be either onedirectional or circular (Schwarz, 1994). Circular interrelationships imply the presence of feedback that is negative when the effect diminishes the cause, or positive when the effect amplifies the cause and makes the system evolve toward a new state (von Bertalanffy, 1968; Schwarz, 1994). The set of indicators should then help assess the directionality of the system in time, in space, and in regard to the finality-finality being the goal of the system. Through modeling the system phenomena and feedback, the set of indicators could then create an urban observatory to pilot the local development.

The approach adopted in our RIM method uses a relational set of interlinked indicators. Indeed it enables one to better analyze complexity by expressing consequences for the whole system following an alteration of one or several indicators. It finally assesses how far a system has evolved toward its goal.

\section{Methodological proposal: the Relational Indicatorset Model (RIM)}

In order to design and analyze a set of indicator, we propose a method based on a Relational Indicatorset Model (RIM). We define indicatorset as a coherent set of indicators, structured through the RIM.

The RIM method (Fig. 1) follows six stages:

Stage 1: Define the RIM-objectives;

Stage 2: Design the RIM graph;

Stage 3: Create the indicatorset;

Stage 4: Position and analyze the indicatorset;

\footnotetext{
${ }^{4}$ http://www.sustainable-cities.org/.

${ }^{5}$ We assume that the aggregation of basic indicators in indexes is an example of interrelationships.
} 


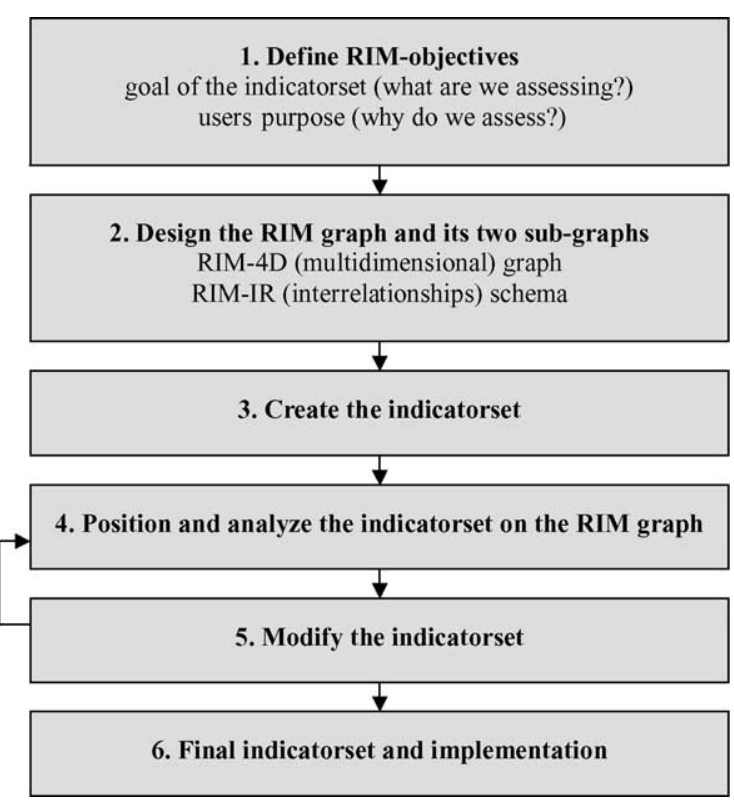

Fig. 1. The six stages of the RIM method.
Stage 5: Modify the indicatorset;

Stage 6: Final indicatorset and implementation.

\subsection{RIM relational graph for modeling the indicatorset}

The core component of the RIM approach is a relational graph used for modeling the indicatorset (Fig. 2). This graph is structured with regard to four dimensions: strategic dimension, spatial dimension, aggregation dimension, and themes. The first three dimensions are ordinal and are represented as three axes on the RIM graph. Themes are nominal and do not appear as an axis; instead they are represented by graphic patterns. The RIM graph highlights the position of each indicator relative to the other indicators of the set, the distribution of the indicatorset relative to each dimension (strategic, spatial, aggregation, and themes), and the internal interrelationships between the indicators of the set. This allows cross-analyzing the indicatorset at two complementary levels: on the one hand, in regard to the goals and users' purpose (of the indicatorset and not those of the indicators taken individually), and on the other

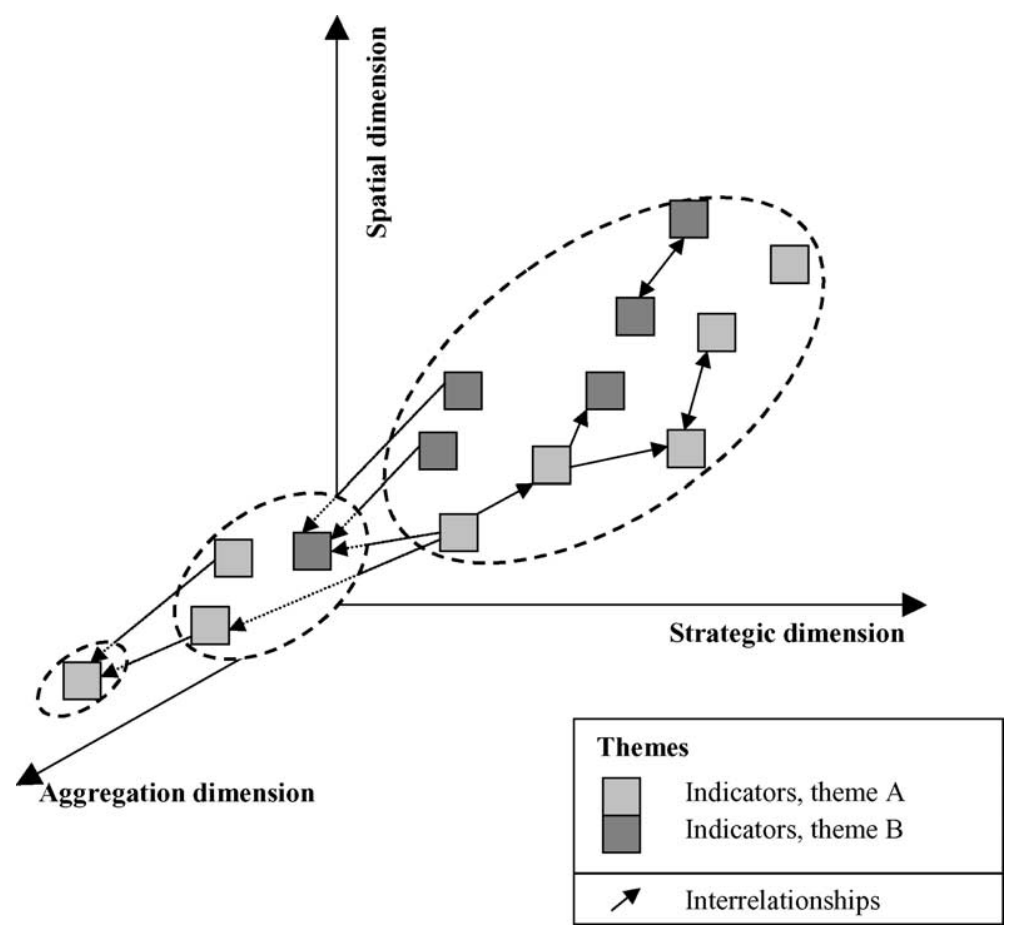

Fig. 2. RIM graph for an indicatorset. 
hand, in regard to the aggregation and causality interrelationships between the indicators.

Practically, this double analysis is made easier by breaking down the RIM graph into two complementary projections:

- First, in the RIM-4D graph that focuses on the distribution of the indicators relative to the four dimensions (strategic, spatial, aggregation, and themes).

- Second, in a RIM-IR schema that displays the internal interrelationships of aggregation and causality.

\section{2. $R I M-4 D$}

The RIM-4D graph provides links between the indicatorset and the RIM-objectives, which are specific to the context. The RIM-4D expresses the RIM-objectives according to four-dimensional axes:

- The Strategic dimension has three levels: Operation, Management/Administration, and Policy/Strategy. The information used to define policies is not the same as the one used for the management of a given sector of activity, and vice versa (van Kamp et al., 2003). Thus, the strategic decision-maker will need global indicators, the manager will prefer more technical information, and the operator will turn to a set of data specific to his/her sphere of activities. The one or many targeted levels for the implemen- tation of the indicatorset thus have to be clearly identified.

- The Spatial dimension has four levels: Infrastructure/Block, Neighborhood, Municipality, and Conurbation. The perception of a problem is not the same at a local scale (an infrastructure, a street, a group of houses) as it is at a global scale (from the smallest administrative district or commune, to a city and its suburbs or conurbation). Therefore, it is important to propose indicators for the different levels of analysis and according to the relevant geographic areas (Allen, 2001; van Kamp et al., 2003).

- The Aggregation dimension has three levels: Basicindicator, Sector-index and Overall-index. The multiplicity of data and simple indicators that are little aggregated offers the possibility of a thorough analysis of a situation, even though an index is more representative of a global phenomenon and is easier to follow over time and to compare with other cities.

- The Themes concern very diverse questions: demography, infrastructure and public services, economy and activities, social welfare, environment, etc. The indicatorset must represent all the themes of the evaluation goal. Some complementary indicators can be intersector to express the relationships among themes. They can even be transsector, aggregating values from different themes.

- The design of the RIM-4D (Fig. 3) is based on the RIM-objectives. On each of the four axes, target lev-

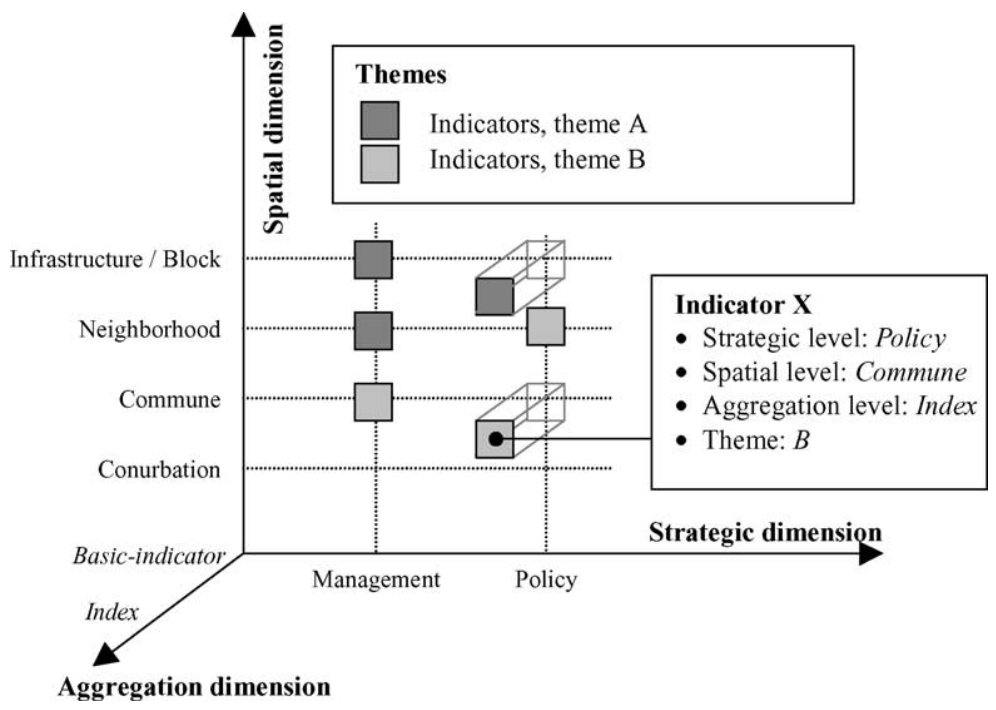

Fig. 3. RIM-4D decomposition of the RIM graph. 
els are defined, for example, a single strategic dimension (Policy) in the case of a system intended for a single decision-maker, but two strategic dimensions (Policy and Management) in the case of a participatory management forum.

The indicatorset is then created and located on the RIM-4D graph. The analysis of its distribution, with regard to the predefined objectives, enables the identification of biases, and then, if necessary, the modification of the indicators.

\section{3. $R I M-I R$}

After the use of the RIM-4D graph to analyze and modify the indicatorset, the indicators are hierarchically and thematically organized. However, the relationships of interdependency are not taken into account at this phase. The next step will be to complete the modeling of the indicatorset to conceptually represent the internal interrelationships on the RIM-IR schema.

The modeling of the interrelationships is based on the three following stages (Fig. 4):

- First, identify the wished trend of the indicator. This is a matter of deciding if an indicator will be maximized or minimized, with regard to a goal.

- Second, identify the possible interrelationship between each pair of indicators and the direction of this interrelationship (plotted with an arrow), which
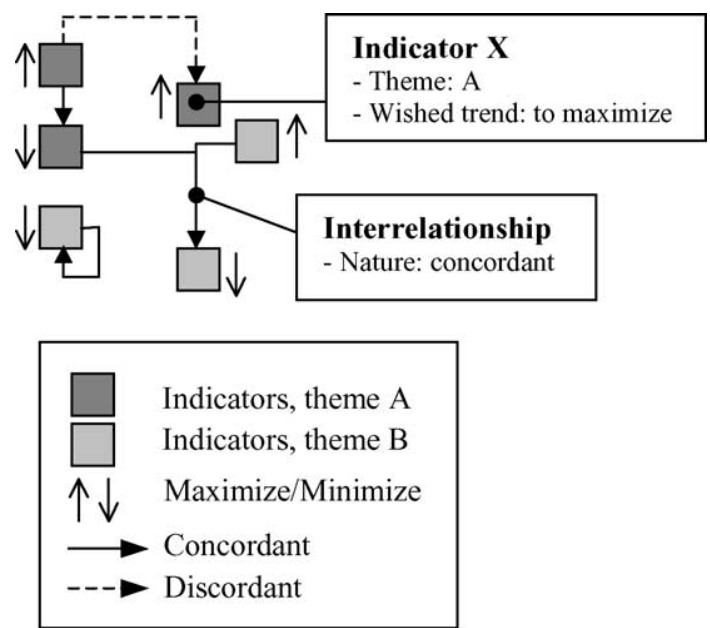

Fig. 4. RIM-IR decomposition of the RIM graph. can be linear or circular (in case of positive or negative feedback).

- Third, identify the nature of each interrelationship. An interrelationship between two indicators A and B can be concordant, when an increase in the indicator A results in an increase in the indicator B (moved together in a common direction), discordant when an increase in the indicator A results in a decrease in the indicator B (opposite direction).

Analyzing the RIM-IR schema, it is possible to assess qualitatively the impact of an indicator on the others and thus to define globally if the system evolves towards its goal. When one wishes to optimize one concrete goal of the urban system represented by a certain indicator, it is possible to assess if the consequences will be harmful to the whole system or parts of it. In the complex system of the city, such negative impacts are frequent. They highlight the importance of considering indicators in interrelationships within a system rather than studying them separately.

\section{Case studies}

In order to illustrate the RIM approach, we present its application in two case studies: (i) an indicatorset for a strategic urban planning instrument in Thies, Senegal, and (ii) an indicatorset for a neighborhood participatory evaluation of the urban conditions in Geneva, Switzerland. These case studies are complementary; each highlights different components of the methodological approach. In Thies, the focus is mainly on the design of the RIM graph and on the analysis of the distribution of the indicators; in Geneva, the case study highlights the RIM-IR modeling of the aggregation and causality interrelationships between the indicators.

\subsection{Indicatorset for strategic urban planning in Thies}

\subsubsection{Context}

Third largest urban area in Senegal in terms of population, Thies is a classical example of a mid-sized developing city, as presented in Table 1. The urban area is made up of two concentric communes ${ }^{6}$ : the first one is

\footnotetext{
6 The "commune" is the local political and administrative level in the Senegalese administration.
} 
Table 1

Development indicators for the city of Thies

City of Thies, Republic of Senegal

Population in 2000

Demographic growth

Population in 2025 (estimation)

Literacy rate

Poverty rate

Annual budget (2001)

limited to the city center, while the second one includes peripheral neighborhoods and several surrounding villages. The two communes have to face several crucial problems, in particular:

- A constant demand for new settlements, which has resulted in a dramatically increasing informal land occupation, strong land speculation, and conflicts with the surrounding rural villages.

- A conflict that pits the city against the neighboring rural communities due to city expansion that occurs without consultation and transparency.

- Environmental deterioration due to the lack of dumps and the accumulation of waste on vacant land, which requires urgent action.

- Several unhealthy neighborhoods because of the lack of wastewater evacuation systems and frequent flooding caused by the deforestation of the surrounding hills.

Under pressure from community associations, the two communes have started a consultation process with the different stakeholders in land-use management, to create cooperative planning of the city and its environment. This approach took shape in 1999 through the creation of a formal collaborative framework and through the initiation of a participatory urban management process. Since then, representatives from the two communes, from the state, and from the community associations meet many times a year to discuss and propose new development projects.

Thies also received assistance from the Urban $\mathrm{Ob}-$ servatories of Francophone Africa (OVAF). The city has obtained methodological support from the Ecole Polytechnique Fédérale de Lausanne (EPFL) and from ENDA-TW ${ }^{7}$ (Repetti and Prélaz-Droux, 2003).

\footnotetext{
${ }^{7}$ ENDA-TW is an NGO specialized in participatory urban development in developing cities.
}

In order to assist the local actors in their participatory development program, a Planning Support System (PSS) has been created to serve as an exchange platform. This collaborative GIS-based instrument contains a set of indicators, which aims at monitoring the city development as well as at supporting decision making in urban land-use planning and management. The PSS includes a prototype of a viewer interface named System for Monitoring Urban Functionalities (SMURF) that makes its use easier for actors without computer skills (Repetti et al., 2004).

\subsubsection{Design of the indicatorset}

The indicatorset was created based on the RIM method. At the start, the RIM-objectives of the set were formalized (Stage 1), through consultation with the local actors:

- The goal of the indicatorset is the evaluation of the sustainable and harmonious development of the city. It passes through different components: economy, quality of life, society, environment and governance, and through a time perspective.

- The users' purpose of the indicatorset is the collaborative management of urban development through monitoring, controlling, and comparison with the other cities of the OVAF network. It is intended for the different stakeholders involved in the urban management of Thies.

- The definition of the RIM-objectives was used as a basis for the RIM graph design (Stage 2). It started with selecting the targeted levels on each of the four dimensions of the RIM graph:

- The strategic dimension includes two levels in this case: Management (infrastructure planning) and Policy (decision on priorities for intervention and investment).

- The spatial dimension includes four levels in this case: Infrastructure/Block, Neighborhood, Commune, and Conurbation.

- The aggregation dimension includes three levels: Basic-indicator (most of the indicators are few aggregated), Sector-index (aggregated by theme), and Overall-index (the indexes should allow comparing the arenas of intervention, tracking their global evolution, and comparison with other cities).

- The themes include nine themes in this case: Demography, Education, Health, Drinking water, 
Waste, Mobility, Trade, Social activities, and Governance. These themes were defined with the support of the city managers, according to the local priorities and to the availability of data.

Based on this framework, a set of 38 spatial and non-spatial indicators was created (Stage 4 ) by the scientific partners and proposed to the local stakeholders. The indicatorset was then located on the RIM-4D graph (Stage 4) and modified till it matches a good distribution in each dimension (Fig. 5). In this early stage of the RIM approach development, the RIM-4D model was used to analyze the possible aggregation interrelationships, but not the causal interrelationships.

Giving more details for the theme Education will better illustrate the complementarity of the data and in- dicators. The database contains two layers with data on education: School and Neighborhood. School stores the location of each school, as well as the name, the number of classes, the number of pupils, and the associated metadata. Neighborhood stores for each neighborhood the child population and the literacy rate. The stored data for the Education theme are aggregated into six indicators (Table 2):

- Pupils per classroom. This indicator displays a thematic map representing each school with a gray patch. The indicator is positioned on the RIM-4D with a Management strategic level, an Infrastructure/Block spatial level and as a Basic-indicator as aggregation level.

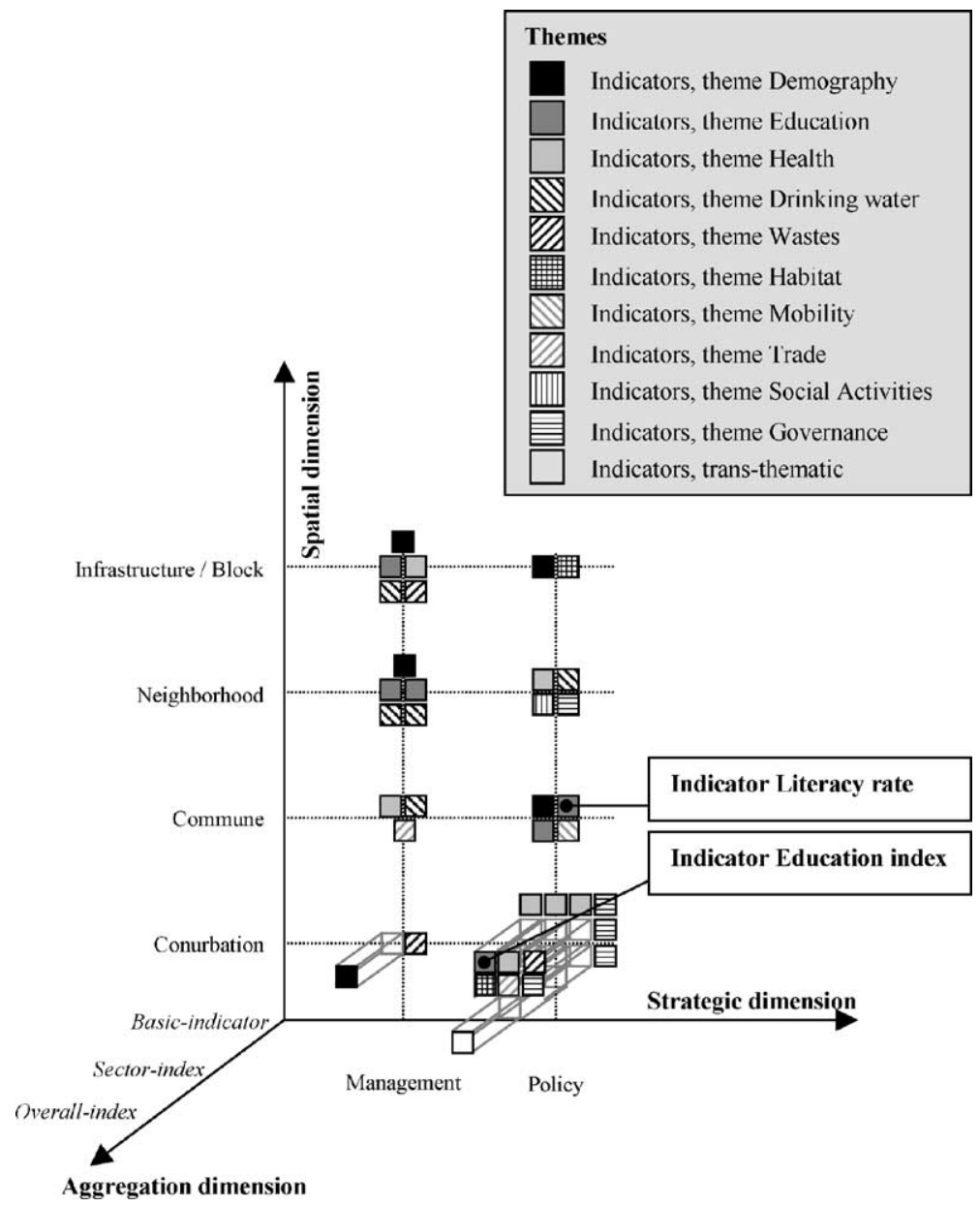

Fig. 5. RIM-4D graph for Thies. 
Table 2

Data and indicators available for the theme Education for Thies

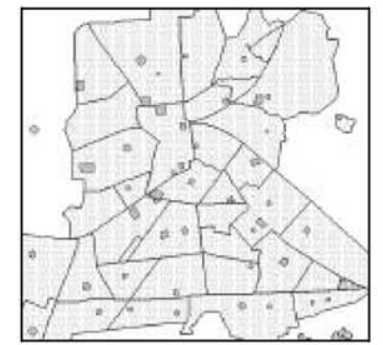

Schools

For each school: location, classrooms, and pupils No aggregation level (data)

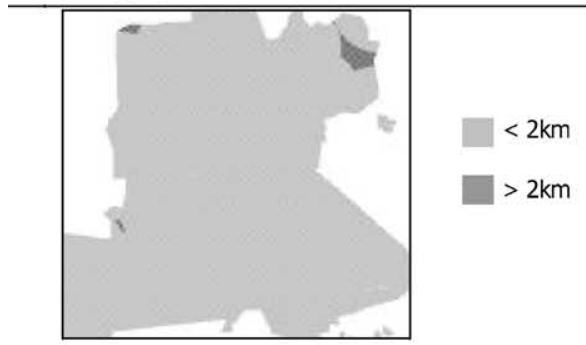

Distribution of schools

Distance to schools from the different neighborhoods Basic-indicator

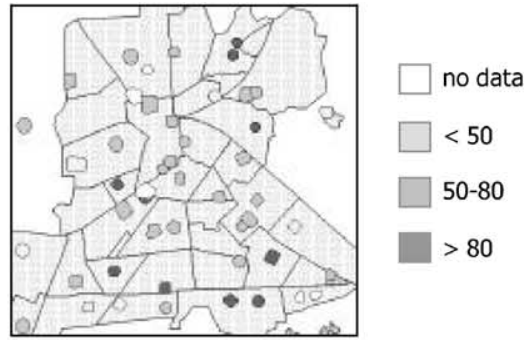

Pupils per classroom

Number of pupils per classroom in each school

Basic-indicator

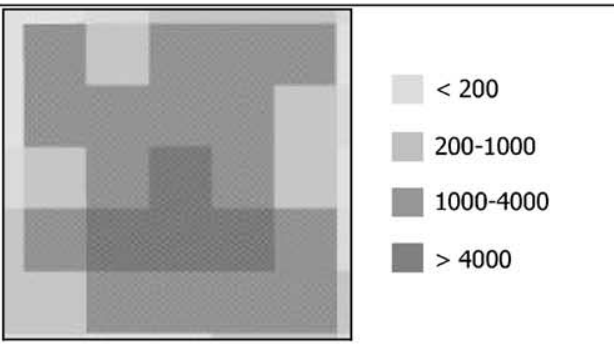

Population in school age

Distribution of the density of children of school age per $\mathrm{km}^{2}$

Basic-indicator

\begin{tabular}{|c|c|c|}
\hline & Villages & $\longleftarrow$ Communes \\
\hline $34.0 \%$ & Ville & \\
\hline $34 \%$ & 1998 & — Historical values \\
\hline $34 \%$ & 1993 & ? \\
\hline $38 \%$ & Dakar & 3. Reference city \\
\hline
\end{tabular}

\section{Literacy rate}

Proportion of the population with literacy skills in French

Basic-indicator

Proportion of the children of school age who are registered in the schools

Basic-indicator

\begin{tabular}{|c|c|}
\hline 21.0 & zone IMAP $\longleftarrow$ Conurbation \\
\hline 52.0 & Afrique ? \\
\hline 62.0 & Reference cities \\
\hline 29.1 & Lagos \\
\hline
\end{tabular}

\section{Education index}

$0.5 \times$ education rate $+0.5 \times$ literacy rate (average of primary education, high school, and university)

Value between 0 and 100

Sector-index

- Distribution of schools. This displays map showing the distance to the nearest school for all the habitat clusters. Its position on the RIM-4D is Management strategic level, Neighborhood spatial level, and Basic-indicator aggregation level.
- Population of school age. This spatial indicator is a grid at 1-km resolution that shows the number of potential pupils. On the RIM-4D, it has a Management strategic level, Neighborhood spatial level, and Basic-indicator aggregation level 
- Education rate. This indicator gives a numerical value for each commune to compare historical values. Its position on the RIM-4D is Policy strategic level, Commune spatial level, and Basic-indicator aggregation level.

- Literacy rate. This indicator presents a numerical value for each commune to compare with historic values. Its position is the same as for the Education rate.

- Education Index. This indicator gives a numerical value for the urban area in comparison to compare with historical values and other cities. Its position on the RIM-4D is Policy strategic level, Conurbation spatial level, and Sector-index aggregation level.

\subsubsection{Discussion}

On the RIM-4D graph, we observe that the distribution of the indicatorset in the cells fits the RIM-objectives. In this case, the distribution is nearly the same between the two strategic levels (Management and Policy). There are indicators on all the spatial levels (Infrastructure/Block, Neighborhood, Commune, and Conurbation). At the aggregation levels, the indicators are mainly Basic-indicator, but there are also seven sector-indexes (total population, education index, health index, waste index, infrastructure index, product index, and total public spending) and one overall-index (City Development Index). Six of the eight indexes are adopted from the work of UN-Habitat (2001), to allow comparisons at the international level. There are indicators for all the nine proposed themes.

The RIM graph then displays the distribution of the indicators, showing the relative placement of each indicator in the set. The graph highlights the match between the goal associated with the indicatorset and the users' purpose objectives. It makes possible an iterative design of the set of indicators, to reach the defined objectives.

The resulting indicatorset then is more than a simple collection of relevant indicators: it is a whole made of complementary indicators. It has been available to the stakeholders in Thies since 2002.

The indicatorset is now part of a broader monitoring system installed in Thies, in the offices of the central administration and of the two involved communes, offering a relevant observatory of urban land use. For the last two years, the information produced has been a source for numerous useful decisions on urban management.

\subsection{Indicatorset for a neighborhood participatory evaluation of the urban conditions in Geneva}

\subsubsection{Context}

Saint-Jean is a neighborhood of 20,000 inhabitants of the city of Geneva, Switzerland. The Ecole Polytechnique Fédérale de Lausanne and the University of Geneva initiated a participatory evaluation of the urban conditions with the collaboration of civil associations (Nembrini et al., 2005). This study is briefly introduced in this section to give the general context of the indicatorset structuring.

The objective of the study, called diagnosis, was to audit the neighborhood conditions and dynamics as a basis for formulating policy actions, and finally improving the environmental quality. This term has been largely defined by many authors (Bonaiuto et al., 2003; Pacione, 2003; van Kamp et al., 2003). It refers in our case to the general satisfaction from the point of view of the inhabitants on natural and built environment, services and facilities, and social interactions (Bonaiuto et al., 2003). Therefore, the diagnosis was not conducted through external expertise, but as a participatory survey, involving inhabitants in the discussion of problems and in sharing information (problem identification). From September to December 2002, several participatory workshops, data acquisition campaigns, and other fieldwork were conducted. A core group of 12 inhabitants constituted the "Diagnosis Group" and took part in all the activities, heading the workshops, providing constant liaison with the other inhabitants, and synthesizing the fieldwork.

The participatory evaluation of the urban conditions is structured into a pyramidal process where information is progressively synthesized (Fig. 6). The 190 concerns about improving environmental quality expressed by the approximately 60 participants (e.g. "too much traffic and noise", "not enough green spaces") are synthesized into 16 ground-goals, and then grouped together into 4 themes (Table 3). A similar study has been done by Bonaiuto et al. (2003) in different neighborhoods of Rome, where hundreds of residents formulated hundreds of 'items' on perceived residential environment quality and neighborhood attachment. 

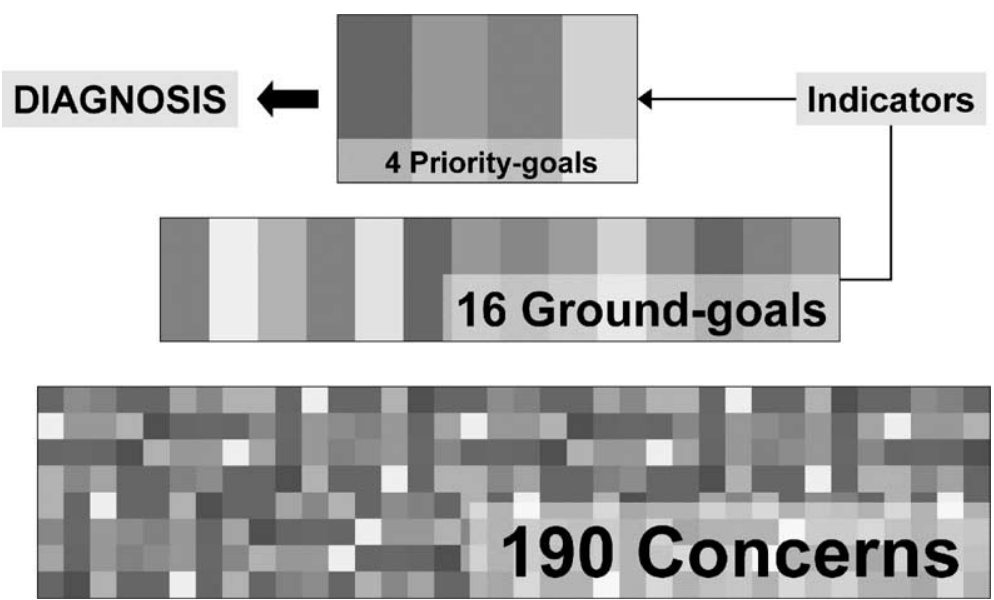

Fig. 6. Pyramidal process for Saint-Jean.

From the collection of ground-goals, experts then designed an indicatorset, which shows the spatial variability of the phenomena within the neighborhood. For instance, the map presented in Fig. 7 shows the indicator noise level at night for various parts of the city. Each gray scaled pixel corresponds to the number of inhabitants exposed to a traffic noise higher than $55 \mathrm{~dB}$ at night. By consulting such maps, inhabitants can compare the situation in their neighborhood with other neighborhoods of Geneva, and with the entire city. They could thus observe and gauge the importance of each ground-goal on their neighborhood and determine the priority-goals that constitute the evaluation of the urban conditions. These priority-goals are the following: (i) to develop social infrastructures, (ii) to regulate parking lots (public and private), (iii) to reduce car speed and noise, and (iv) to stabilize or increase low-rent housing.

This synthesis from the concerns toward the choice of ground-goals, and then priority-goals, is the most fundamental contribution of the involvement of the inhabitants. By using such an evaluation method, public authorities can take into account the real expectations of the population, and decide which actions will be undertaken.

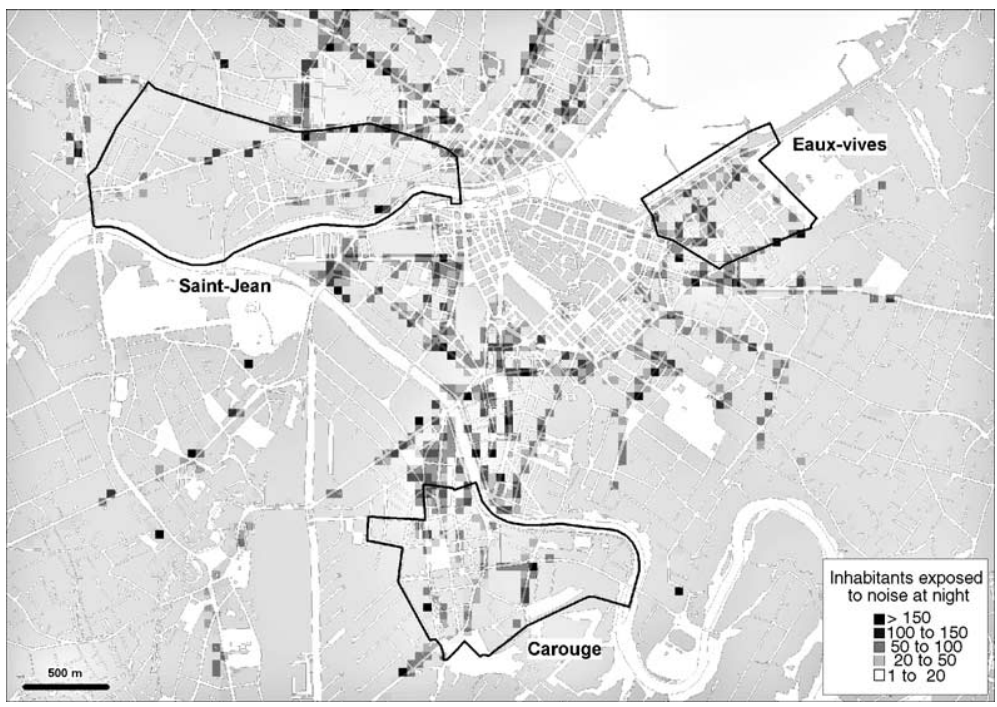

Fig. 7. Inhabitants exposed to noise at night in neighborhoods and in the whole city. 
Table 3

Structure of the indicatorset for Saint-Jean

\begin{tabular}{|c|c|c|c|}
\hline Themes & Ground-goals & Basic-indicators & Indexes \\
\hline \multirow[t]{10}{*}{ Ecomobility } & $\begin{array}{l}\text { To better distribute space designated for the } \\
\text { movement of pedestrians and cyclists }\end{array}$ & Sidewalk width ${ }^{\mathrm{a}}$ & Public space distribution \\
\hline & & $\begin{array}{l}\text { Bike installations (cycle paths } \\
\text { and parking) }\end{array}$ & \\
\hline & & Public transport (PT) path width & \\
\hline & To increase and diversify public transport & PT frequency & \\
\hline & & PT path width & \\
\hline & $\begin{array}{l}\text { To improve attractiveness (safety and } \\
\text { pleasure) of pedestrian movement }\end{array}$ & Public bench density ${ }^{a}$ & Public space attractiveness \\
\hline & & Lighting density ${ }^{\mathrm{a}}$ & \\
\hline & & Traffic density (vehicles/min) ${ }^{\mathrm{a}}$ & \\
\hline & & Sidewalk width ${ }^{\mathrm{a}}$ & \\
\hline & & Small shops attractiveness ${ }^{a}$ & \\
\hline \multirow[t]{7}{*}{ Traffic } & To improve pedestrian safety & Sidewalk width ${ }^{\mathrm{a}}$ & \\
\hline & & School safety & \\
\hline & To reduce car speed and noise & Noise level at night & Inhabitants exposed to noise \\
\hline & & Inhabitant density & \\
\hline & To regulate parking lots (public and private) & Parking per capita & \\
\hline & To decrease traffic movement & Traffic density (vehicles/min) ${ }^{\mathrm{a}}$ & \\
\hline & & Road width & \\
\hline \multirow[t]{7}{*}{ Social life } & To develop social infrastructures & Childcare centers availability & \\
\hline & & Meeting place density & \\
\hline & $\begin{array}{l}\text { To extend social activities to other sectors of } \\
\text { the neighborhood }\end{array}$ & Social activity density & \\
\hline & To promote small trades & Small shops attractiveness ${ }^{\mathrm{a}}$ & \\
\hline & $\begin{array}{l}\text { To stabilize - or even increase - low-cost } \\
\text { housing }\end{array}$ & Low-rent proportion & \\
\hline & To improve social diversity & Social diversity & \\
\hline & To make the neighborhood safer & Delinquent act density ${ }^{\mathrm{a}}$ & \\
\hline \multirow[t]{5}{*}{ Public space } & $\begin{array}{l}\text { To improve respect for facilities and safety in } \\
\text { public spaces }\end{array}$ & Delinquent act density ${ }^{\mathrm{a}}$ & \\
\hline & $\begin{array}{l}\text { To improve development and attractiveness } \\
\text { of public spaces }\end{array}$ & Proximity to parks & \\
\hline & & Public bench density ${ }^{a}$ & \\
\hline & & Lighting density ${ }^{a}$ & \\
\hline & To create places of information exchange & $\begin{array}{l}\text { Places of information exchange } \\
\text { density }\end{array}$ & \\
\hline
\end{tabular}

\footnotetext{
${ }^{\text {a }}$ Inter-thematic indicator.
}

\subsubsection{Design of the indicatorset}

The use of an indicatorset in Saint-Jean aimed to give an overview of the neighborhood with regard to the identified ground-goals. In this case, the emphasis was placed on measurement of relative trends (qualitative controlling) and on comparison with other neighborhoods (benchmarking). At the time of the fieldwork, indicators were identified, organized, and structured in themes and ground-goals, but without considering explicitly their aggregation and causal in- terrelationships. To go beyond this first level of organization, we used the proposed systemic approach to restructure the indicators into a more coherent set.

The representation of the indicators in the RIM graph was carried out using the RIM approach. It resulted in a RIM-4D graph with two strategic levels (Management and Policy), with three spatial levels (Infrastructure/Block, Neighborhood, and City), with two aggregation levels (Basic-indicator and Index), and 
four themes (Ecomobility, Traffic, Social neighborhood life, and Public space). All the indicators are spatial, as space is central in the process and in the identification of the priority-goals.

On the aggregation dimension, 3 of the 24 indicators are aggregated indexes:

- Public space distribution for ecomobility. This index is evaluated for public roadways based on the proportion of space attributed to ecomobility (walkways, bike paths, bus lanes) compared to the space attributed to cars (parking and roads).

- Public space attractiveness. This index aggregates two concerns and three indicators. It evaluates the factors that make a public space pleasant to walk in: Shops density (with windows), Limitation of traffic to improve quietness and safety, Lighting density, Public bench density, and Sidewalks width.

- Inhabitants exposed to noise at night. This index connects the density of inhabitants (which is not strictly an indicator in our case since it is not associated to a ground-goal) and the Noise level at night.

Among these indexes, the two first are transthematic, in particular Attractiveness of public space, which groups basic-indicators coming from the four themes (Ecomobility, Traffic, Social neighborhood life, and Public space).

The resulting indicatorset is designed based on the list of ground-goals. But, some ground-goals are measured by one basic-indicator and some by several (up to four). Then again, some indicators (e.g. Traffic density, Sidewalk width and Small shops attractiveness) are inter-thematic as they are associated with more than one ground-goal and theme, which produces some redundancy of information.

To go further in structuring the indicatorset, the project partners wanted to express the interrelationships between the indicators, and thus indirectly between the ground-goals, to better comprehend the urban conditions, to identify contradictory tendencies, and to assess the potential evolution.

\subsubsection{Application of the RIM-IR schema}

The diagnosis is enriched by analyzing, not only the state of the neighborhood, but also its functioning in order to improve the relevance of further actions. This is done by creating a model of the interrelation- ships between the indicators. An expert could create such a model by measuring statistical correlations for instance. But we assume that every urban stakeholder - such as an inhabitant, institutional manager, or scientist - has an intuitive perception of the functioning of the urban system as a day-to-day empirical observer of urban phenomena. This assumption is based on the second-order cybernetics principle that says that the observer is a part of a system's construction and consequently a system is the subject of understanding of one or several people (Bell and Morse, 2000). Therefore, six members of the Diagnosis group took part in the elaboration of the RIM-IR schema for the indicatorset. Each one identified a set of interrelationships between the indicators.

The six models, corresponding to each member of the Diagnostic group, were gathered into a synthetic model, including only the interrelationships that were expressed by one third of the participants (empirical choice that corresponds to a minimum of two of the six participants in our case). In the end, these interrelationships gave a convergent view of the most relevant elements and relationships to represent the urban system (Fig. 8). It opens up to an overview of the potential evolution of the system through the expression of the causal interrelationships expressed by the Diagnosis group.

The indicators are located within the four themes or between them for the inter-thematic indicators. The aggregation interrelationships are not represented explicitly, because the indexes are linked to all their basic indicators (which are grouped into the dark-gray boxes on the figure). Furthermore, the Diagnosis group identified some causal interrelationships between the indexes and the basic-indicators, for instance between Public space attractiveness and Meeting place density or Social activity density.

\subsubsection{Analysis of the RIM-IR schema}

Globally the RIM-IR schema confirms the prioritygoals formulated during the participatory diagnosis. We observe one main action point linked to Traffic density where a few easily recognizable concrete actions might quickly improve the quality of life. The inhabitants are requesting less Traffic density since they consider it a source of nuisance (insecurity, noise, traffic jam). At the same time, they ask for an increase in Public spaces' attractiveness by increasing ecomobile 


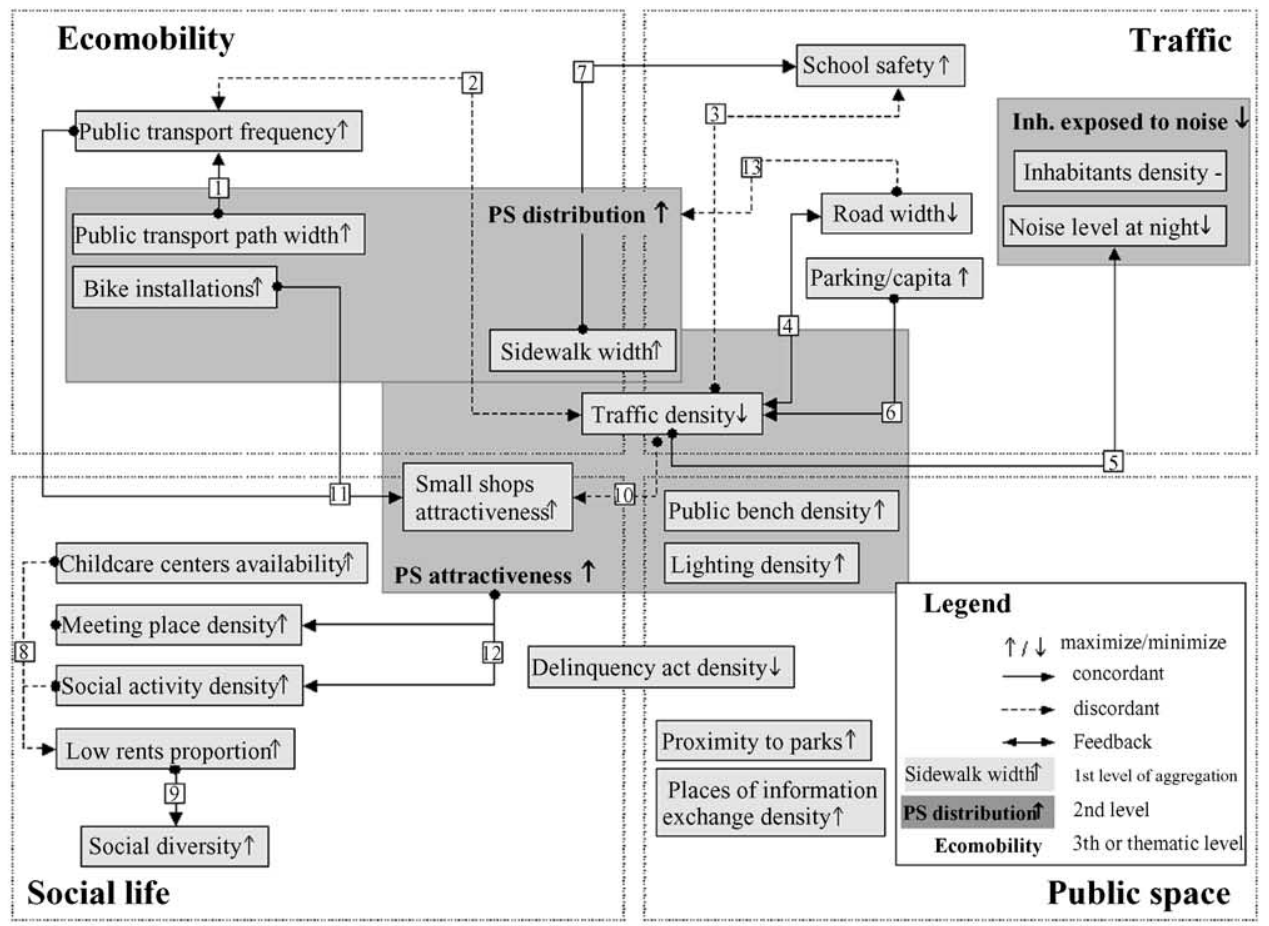

Explanation of the interrelationships:

1. Public transport frequency will be better if the public roadway contains corridors reserved for this means of transport.

2. An increase in traffic may compete with public transport and disturb the frequency (cause delays). This phenomenon can be amplified through a positive feedback.

3. An increase in traffic may decrease safety around schools.

4. An increase in traffic may require a widening of the road, which in turn can lead to a further increase in traffic.

5. An increase in traffic may cause an increase in noise level and consequently in disturbances for inhabitants.

6. More parking availability may encourage people to use their vehicles.

7. Broader sidewalks improve safety around schools.

8. Improvement of living conditions in the neighborhood through greater proximity and accessibility may involve an increase in the rents, and can therefore decrease low-rent housing.

9. More low rents would attract people with low incomes, which would improve social diversity .

10. As small shops are generally more accessible by ecomobile modes of transportation (foot, bicycle, bus), a decrease in traffic makes them more attractive.

11. Better public transport frequency and more bike installations close to small shops makes the latter more attractive.

12. An attractive public space contributes to attract new activities, which increases the density of meeting places.

13. An increase in road width logically decreases the proportion of space given to ecomobility.

Fig. 8. RIM-IR schema for Saint-Jean.

transport, making public spaces more attractive, and improving therefore neighborhood social life. Public authorities should prioritize intervening in this action point so as to make the system evolve toward its goal. The RIM-IR schema proposes one solution to counter- act Traffic density by acting on public transportation frequency.

Following these considerations, some details of the RIM-IR schema can be analyzed to reveal the usefulness of the RIM methodology: 
- First, the model reveals some feedbacks resulting from direct or indirect mechanisms. The interrelationship between Traffic density and Public transport frequency constitutes a good example of a positive feedback. Yet it involves other intermediate interrelationships, which concern the space allocated to the various modes of transport: an increase in Traffic density induces more space available (Road width) to the detriment of Public transport path width (through its interrelationship with Public space distribution for ecomobility), which results in worsening Public transport frequency. Consequently, inhabitants will be more encouraged to use private vehicles. Beyond a critical point, such a positive feedback can be inversed and become negative or regulating. Indeed, extending the analysis to the spatial dimensions, the increase of private vehicle use leads to traffic jams. Therefore, the authorities may decide to improve public transport services by building new bus paths, and thus encourage people to use their cars less.

- Second, the RIM-IR schema reveals some contradictory ground-goals. For instance, the stakeholders wish simultaneously to maximize Parking per capita and minimize the Traffic density. But an increase in Parking per capita may encourage people to use their vehicles more. This illustrates that it might appear judicious to optimize a situation from the point of view of one indicator, but the consequences for other aspects of the system could be harmful.

- Third, interrelationships are not always linear. The case of the interrelationship between Low-rent proportion and Social diversity can illustrate this fact. In a rather well-off neighborhood, the building of new subsidized housing would attract low-income people and contribute to better social diversity. However, this trend is not linear: if too much subsidized housing is built, the global income of the population becomes too low and the social diversity decreases again and reverses the process. Consequently, the relationship changes from a concordant to a discordant trend, according to a parabolic function.

\subsubsection{Discussion}

In the early evaluation stage of a decision process, the modeling of the systemic interrelationships between indicators by stakeholders does not aim to express an exhaustive and objective truth. It is more a kind of brainstorming stage that helps stakeholders to build their own representation of the city. By elaborating a relational indicators system, the urban complexity is more easily perceived, and the goals and priorities are better identified.

But in Geneva, the relational system of the set of indicators was produced a posteriori, after the participatory diagnosis was achieved. Consequently, the initial indicatorset was not defined using the RIM or with a systemic model in mind. Indeed, the RIM graph reveals that the three indexes do not reflect all the ground-goals and all basic-indicators; they only give a partial view of the situation that must be completed. Moreover, some indicators appear to be redundant and others marginal (no interrelationship). Subsequently, the RIM approach provides a guide for selecting and aggregating indicators that result in a synthetic view of the urban conditions, better targeting data collecting to measure the indicators, and designing in the end a more relevant indicatorset.

The indicatorset can become an operational tool to describe and to understand the functional character of an urban system at a particular moment. This will help to anticipate possible harmful consequences on the whole urban system of certain decisions and help to identify possible action points. In a later stage, if the indicators are regularly updated, the system could be used as an urban observatory.

\section{Conclusion}

Urban planning and management is turning more and more frequently to indicators to monitor and control land-use development. Such instruments need to be particularly adapted to complex and dynamic management problems. They allow a continuous audit of the development and its sustainability, for a better understanding of the urban realities. The ideal set of indicators will vary from one city to the other, in regard of the development conditions, traditions, and policies.

Indicators give an indirect evaluation of urban land use through displaying an image of the city. The quality of this image is thus vital: it depends on the accuracy of each indicator modeling, but also on the ability of the whole set of indicators to coherently and relevantly highlight the different facets of urban development. 
While current approaches to information structuring propose very complete relational models for designing databases (Conceptual Data Models), the design of sets of indicators remains generally limited to the technical requirements of data processing (formulas, form, relevance, utility of each indicator). They little consider the structure and the functionalities of the resulting set taken as a whole. Indicators are therefore usually compiled within statistical catalogues and without representation of the causal interrelationships.

To improve information management, the RIM modeling proposes a methodological approach to design sets of indicators. It has potential to support the complex processes of land-use monitoring, particularly in urban planning and management. The proposed approach starts from the hypothesis that the relevance of an indicator is not only linked to its intrinsic qualities, but also to its placement and relationships to the other indicators of the set. It emphasizes the links between the set of indicators, its users' purpose, and the goal of the urban system.

The RIM approach consists of a graph and its two complementary projections (RIM-4D and RIM-IR). First, the indicators are positioned on a RIM-4D graph defined by four dimensions related to the goal and users' purpose: the strategic, spatial, and aggregation dimensions and the themes. Second, the RIM-IR is used to display the causal and aggregation interrelationships between the indicators of the set. The analysis of the distribution of the indicators in the RIM graph highlights the adequacy of the indicatorset with its goals and the users' purpose; by revealing the interrelationships, the RIM supports decision making by providing an overview of the land-use dynamics and a clarification of intersector concerns.

The two case studies highlight different facets of the use of the RIM. The Thies example focuses mainly on the distribution of the indicators, when the Geneva example adds a complete analysis of interrelationships. The global approach supports urban land-use planning and management, by providing a common understanding not only of the indicators (components of the system), but also of their dynamics, interrelationships, and links with the goal of the whole system. Similarly, the case studies emphasize the need for defining early in the process a coherent set of ground-goals and indicators with a systemic approach. They also show that the design of the RIM graph helps to identify not only the interrelationships between the indicators of a set, but also the targeted synthetic levels, spatial levels, aggregation levels, themes and ground-goals. In other words, the RIM establishes an intersector-based and multidisciplinary view of urban complexity; such models are necessary requested when the goal of information systems is to support planning and decision-making for the sustainable development of cities.

The RIM methodology remains a prototype, demonstrating original conceptual principle; but faces with limitations in practice:

- The two case studies present an evaluation of the urban conditions at a given time with the help of indicators. But monitoring is a continuous evaluation, so tracking the objectives over time is necessary to permit a dynamic analysis of the evolution of the land development. This can be done by periodically updating the indicators, allowing trends to be identified. More ambitiously, the causal interrelationships presented in the relational indicators system can be simulated, implying the need for mathematical equations to model them.

- Another question is whether the independence of the dimensions constituting the axes of the RIM graph is independent one from the other. Indeed, an aggregated index is generally located at high strategic level; and one generally makes the opposite assumption of a correlation between the operational level and local scale. The RIM approach does, however, not establish the validity of such correlations, but offers a basis for analysis that highlights the links to and coherency with the goals of the users.

By analyzing a posteriori existing sets of indicators, the use of the RIM approach offers very interesting possibilities for the monitoring and modeling of complex situations. This RIM approach can easily be extended to other land-use planning and management contexts, such as rural community development, environmental management, or risk management. The suggested methodology also offers opportunities to reinforce the effectiveness of local Agenda 21 tools and their monitoring, in particular in the identification of problems and their causes.

Finally, the RIM approach supports the elaboration of policies and possible actions from a set of indicators. It allows the identification of the sensitive areas in which compromises and negotiations should be under- 
taken, the potentially conflicting goals and the potential action points. Therefore, it offers a solution to go from collective values expressed through indicators to concrete actions.

\section{Acknowledgments}

This paper describes activities carried out within the context of two different research projects on participatory urban planning and management.

- The IMAP-Thies project (Instruments and Models for Participatory Planning) was headed at the Ecole Polytechnique Fédérale de Lausanne (EPFL) jointly by the Hydrology and Land Improvement Laboratory and by the National Center for Competence in Research North-South. The project was funded by the Swiss National Science Foundation and the Swiss Agency for Development and Cooperation.

- The CITYCOOP-Geneva project was headed by the Geographic Information Systems Laboratory and the Hydrology and Land Improvement Laboratory of the Ecole Polytechnique Fédérale de Lausanne (EPFL) and by the Center for Human Ecology and Environmental Sciences of the University of Geneva. The project was funded by the European Network COST C9 "Processes to reach urban quality".

\section{References}

Allen, E., 2001. INDEX: software for community indicators. In: Brail, R.K., Klosterman, R.E. (Eds.), Planning Support Systems. ESRI Press, Redlands, pp. 229-261.

Ambiante Italia, 2003. European Common Indicators. Ambiante Italia Publication, Milano.

Bell, S., Morse, S., 2000. Sustainability Indicators: Measuring the Immeasurable. Earthscan, London.

Bolay, J.-C., Pedrazzini, Y., Rabinovich, A., 2000. Quel sens au développement durable dans l'urbanisation du tiers monde. Les Annales de la Recherche Urbaine 86, 77-84.

Bonaiuto, M., Fornara, F., Bonnes, M., 2003. Indexes of perceived residential environment quality and neighbourhood attachment in urban environments: a confirmation study on the city of Rome. Landscape Urban Plan. 65, 41-52.

Borja, J., Castells, M., 1997. Local and Global: Management of Cities in the Information Age. Earthscan, London.

Carmona, M., Burgess, R., 2001. Strategic Planning and Urban Projects. Delft University Press, Delft. de Montmollin, A., Altwegg, D., 2000. Sustainable Development in Switzerland. Swiss Federal Statistical Office, Neuchâtel.

Gallopin, G.C., 1997. Indicators and their use: information for decision-making. In: Moldan, B., Billharz, S. (Eds.), Sustainability Indicators. Wiley, Chichester, pp. 13-27.

Geertman, S., Stillwell, J., 2003a. Planning support systems: an introduction. In: Geertman, S., Stillwell, J. (Eds.), Planning Support Systems in Practice. Springer, Berlin, pp. 3-22.

Geertman, S., Stillwell, J., 2003b. Interactive support systems for participatory planning. In: Geertman, S., Stillwell, J. (Eds.), Planning Support Systems in Practice. Springer, Berlin, pp. 25-44.

GHK Group, 2000. City Development Strategies: Taking Stock and Signposting the Way Forward. DFID and World Bank Publications, London.

Hammond, A., Adriaanse, A., Rodemburg, E., Bryant, D., Woodward, R., 1995. Environmental Indicators: A Systematic Approach to Measuring and Reporting on Environmental Policy Performance in the Context of Sustainable Development. World Resources Institute Publications, Washington.

Harris, B., Batty, M., 2001. Locational models, geographic information, and planning support systems. In: Brail, R.K., Klosterman, R.E. (Eds.), Planning Support Systems. ESRI Press, Redlands, pp. 25-57.

Harts, J.J., Maat, K., Ottens, H., 2003. Planning support systems: an introduction. In: Geertman, S., Stillwell, J. (Eds.), Planning Support Systems in Practice. Springer, Berlin, pp. 315-329.

Huang, S.-L., Wong, J.-H., Chen, T.-C., 1998. A framework of indicator system for measuring Taipai's urban sustainability. Landscape Urban Plan. 42, 15-27.

IFEN, 1998. Test des Indicateurs de Développement Durable des Nations Unies: Rapport de la France. Institut Français de l'Environnement, Orléans.

Ingallina, P., 2001. Le Projet Urbain. Presses Universitaires de France, Paris.

Joerin, F., Rey, M.C., Nembrini, A., Desthieux, G., 2001. Information et participation pour l'aménagement du territoire. Revue Internationale de Géomatique 11 (3/4), 309-332.

Lautso, K., 2003. The SPARTACUS system for defining and analyzing sustainable urban land use and transport policies. In: Geertman, S., Stillwell, J. (Eds.), Planning Support Systems in Practice. Springer, Berlin, pp. 453-463.

le Galès, P., 1998. Regulation, territory and governance. Int. J. Urban Regional Res. 22 (3), 482-506.

Luz, F., 2000. Participatory landscape ecology-a basis for acceptance and implementation. Landscape Urban Plan. 50, 157-166.

Malkina-Pykh, I., 2002. Intergrated assessment models and response function models: pros and cons for sustainable development indices design. Ecol. Indicators 2, 93-108.

Merkle, A., Kaupenjohann, M., 2000. Derivation of ecosystemic effect indicators-method. Ecol. Model. 130, 39-46.

Naveh, Y., 2000. What is holistic landscape ecology? A conceptual introduction. Landscape Urban Plan. 50, 7-26.

Naveh, Y., 2001. Ten major premises for a holistic conception of multifunctional landscapes. Landscape Urban Plan. 57, 269-284.

Nembrini, A., Billeau, S., Desthieux, G., Joerin, F., 2005. GIS and participatory diagnosis in urban planning: a case study in Geneva. 
In: Campagna, M. (Ed.), GIS for Sustainable Development. Taylor \& Francis, London, pp. 451-465.

Newman, P.W.G., 1999. Sustainability and cities: extending the metabolism model. Landscape Urban Plan. 44, 219-226.

OECD, 1988. Towards Sustainable Development: Environmental Indicators. OECD Publications, Paris.

OECD, 1993. OECD Core Set of Indicators for Environmental Performance Reviews. OECD Publication, Paris.

OECD, 1997a. Better Understanding our Cities: The Role of Urban Indicators. OECD Publication, Paris.

OECD, 1997b. Toward Sustainable Development: Environmental Indicators. OECD Publication, Paris.

OECD, 2001. Society at a Glance: OECD Social Indicators. OECD Publication, Paris.

Pacione, M., 2003. Urban environmental quality and human wellbeing - a social geographical perspective. Landscape Urban Plan. 65, 19-30.

Palang, H., Mander, U., Naveh, Z., 2000. Holistic landscape ecology in action. Landscape Urban Plan. 50, 1-6.

Prescott-Allen, R., 1995. Barometer of Sustainability: A Method of Assessing Progress Toward Sustainable Societies. IUCN Publication, Cambridge.

Rechatin, C., Theys, J., Lavoux, T., Piveteau, V., 1997. Indicators of Sustainable Development: A Synopsis of Work Abroad and Key Points for Discussion. Publication of Institut Français de l'Environnement, Orléans.

Repetti, A., Prélaz-Droux, R., 2003. An urban monitor as support for a participative management of developing cities. Habitat Int. 27, 653-667.

Repetti, A., Soutter, M., Musy, A., Radke, J., 2004. System for Monitoring Urban Functionalities (SMURF): instrument, method and application. In: Proceedings of the 42nd URISA Annual Conference, Reno, pp. 408-420.

Schwarz, E., 1994. A metamodel to interpret the emergence, evolution and functioning of viable natural systems. In: Cybernetics and Systems. Trappl, Vienna, pp. 1579-1586.

Shafer, C.S., Lee, B.K., Turner, S., 2000. A tale of three greenway trails: user perceptions related to quality of life. Landscape Urban Plan. 49, 163-178.

Spangenberg, J.H., Pfah, S., Deller, K., 2002. Toward indicators for institutional sustainability: lessons from an analysis of Agenda 21. Ecol. Indicators 2, 61-77.

Srinivas, H., 1999. Urban environmental management: a partnership continuum. In: Inoguchi, T., Newman, E., Paoletto, G. (Eds.), Cities and the Environment. United Nations University Press, Tokyo, pp. 30-46.
Sustainable Seattle, 1998. Indicators of Sustainable Community. Sustainable Seattle Publication, Seattle.

Tjallingii, S.P., 1993. Ecopolis: Strategies for Ecologically Sound Urban Development. Backhuys, Leiden.

UNDP, 1997. Participatory Local Governance. United Nations Development Programme Publications, New York.

UN-Habitat, 2001. The State of the World's Cities. UN-HABITAT Publications, Nairobi.

UN-Habitat, 2002. Monitoring Urban Conditions and Trends. UNHabitat Publications, Nairobi.

United Nations, 1996. Indicators of Sustainable Development: Framework and Methodologies. United Nations Publications, New York.

van Kamp, I., Leidelmeijer, K., Marsman, G., de Hollander, A., 2003. Urban environmental quality and human well-being; towards a conceptual framework and demarcation of concepts; a literature study. Landscape Urban Plan. 65, 5-18.

von Bertalanffy, L., 1968. General System Theory. George Braziller, New York.

von Stokar, T., Frick, R., Schultz, B., Keiner, M., Rey, M., Mettan, N., 2001. Planification Directrice Cantonale et Développement Durable. Publications de l'Office du Développement Territorial, Berne.

World Bank, 2002. Local Economic Development. World Bank Publications, Washington.

Alexandre Repetti (1973) is a researcher in the Hydrology and Land Improvement Laboratory of the Ecole Polytechnique Fédérale de Lausanne (EPFL). He is an environmental engineer specialist on regional and environmental planning, involving collaborative GIS and decision support systems. He gives lectures on land-use and environmental management for developing countries and is a fellow of the Swiss National Center of Competence in Research Partnerships for Mitigating Syndromes of Global Change. Working on the theme of improving urban governance, Thies, Senegal, has been a relevant field for testing his theoretical propositions and for his Ph.D. that received the 2004 Lausanne Research and Innovation Award.

Gilles Desthieux (1976) is a researcher in the Geographical Information Systems Laboratory of the Ecole Polytechnique Fédérale de Lausanne (EPFL). He received his degree in environmental engineering in 2000. He accomplished in 2005 a Ph.D. on indicator set structuring by a systemic and participatory approach in the urban management context. This work came within the scopes of a project on participative diagnosis in land-use planning in Geneva, and a survey of urban spreading issue in Quebec city, in partnership with the University Laval. 